\title{
The application of GIS to air quality analysis in Enna City (Italy)
}

\author{
F. Patania, A. Gagliano, F. Nocera \& A. Galesi \\ Energy and Environment Division of D.I.I.M., \\ Engineering Faculty of University of Catania, Italy
}

\begin{abstract}
Air quality models play a very important role in formulating air pollution control and management strategies by providing information about better and more efficient air quality planning.

This paper describes an urban air quality modelling system for evaluating the environmental effects of transport related air pollution. A preliminary evaluation of the model has been performed for one site in Enna City using data from an extensive monitoring and measuring campaign. Then the authors utilize a geographic information system (GIS), which integrates a vehicle emission model, pollutant dispersion model and related databases to estimate the emissions and spatial distribution of traffic pollutants. The model can not only analyze the current pollution situations, but also can predict the emissions influenced by exhaust coming from changes in specific traffic conditions or management policies.
\end{abstract}

Keywords: CALINE 4, GIS, air pollution.

\section{Introduction}

Air quality models have a very important role in developing air pollution control and management strategies. Line source models are often used to simulate the dispersion of pollutants near the highways, the roads, roundabouts, bypasses and so on. These dispersion models, mostly Gaussian based, despite several assumptions and limitations, are used by the regulatory agencies to carry out air pollution prediction analysis due to vehicular traffic near the roads as a part of the Environmental Impact Assessment (EIA) procedure. 
The integration of the geographical information system (GIS) with the existing air pollution modelling approach can help the decision making process of the transportation planners who design and implement control strategies.

Authors used GIS in developing microscale analyses of the old town centre of Enna City. They linked a GIS with CALINE 4 to predict pollutant concentration levels.

The value of GIS (outside of spatial data storage and data visualization) was its ability to compare concentration results to other non-related data.

\section{Methodology of research}

The authors have developed and applied a model, which integrated several submodels, such as the emission estimation model, dispersion model and relevant spatial and attribute data in a GIS framework. The entire system is applied to estimating emissions from motor vehicles and analyzing the spatial distributions of air pollutants in the old town centre of Enna city. Figure 1 shows the structure of the entire system.

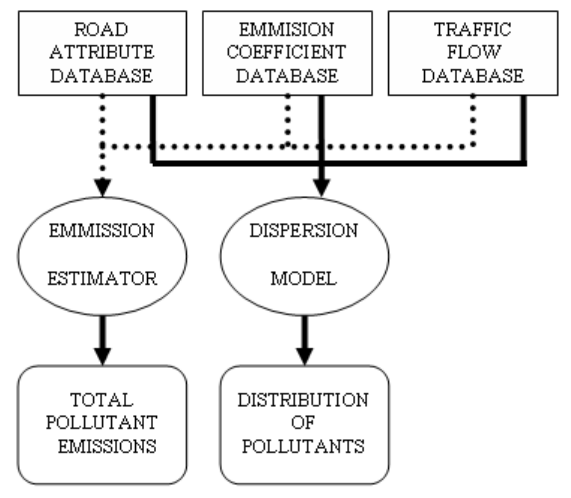

Figure 1: $\quad$ Structure of the GIS system.

The GIS platform used in this research is ArcGIS, a software developed by ESRI, which provides a variety of tools for spatial data exploration, identification of data anomalies, optimum prediction, evaluation of prediction uncertainty, and surface creation.

The research has been carried out in accordance with following steps:

- data acquisition and analysis of traffic flows;

- analysis of meteoclimatic historical data;

- application of COPERT III emission Model

- $\quad$ application of CALINE 4 quality model implemented by Authors

- validation of adopted model through comparison between polluting concentration data forecasted and that ones measured in situ during the campaign of measurements.

- $\quad$ application of GIS Framework 


\section{Study case}

The investigated area is located in the old town centre of Enna city as shown in figure 2. The pollutants selected for study are Carbon Monoxide (CO) and Particular Matter $\left(\mathrm{PM}_{10}\right)$ because they are the typical gas emitted by vehicular traffic.

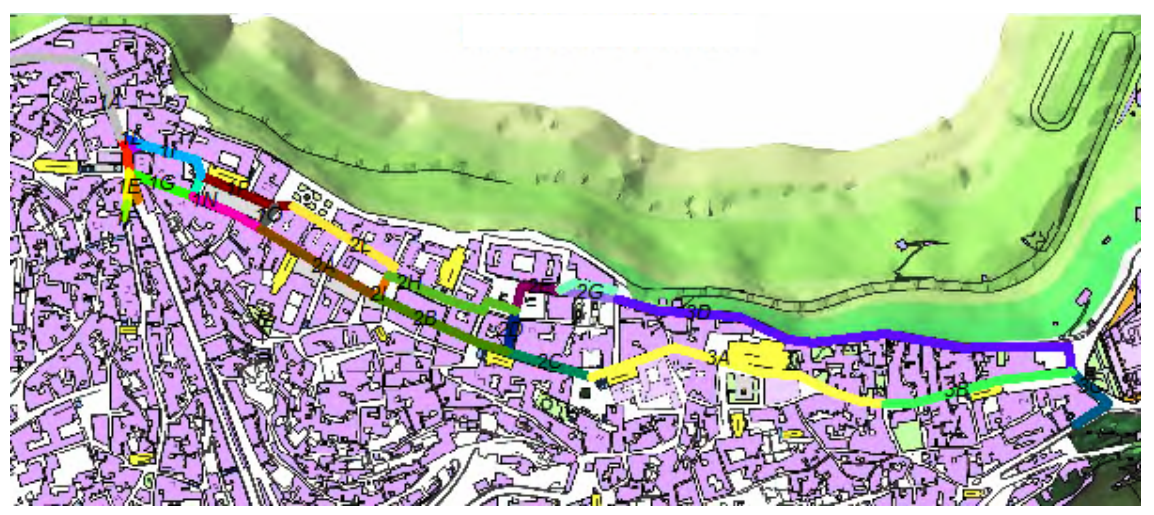

Figure 2: $\quad$ Old town centre of Enna and linked road.

Firstly, the Authors have identified twenty-seven main roads within the survey area and each road was characterized by geometrical features (typology, width and length of carriage way), traffic parameters and georeferenced coordinates.

Geometrically the streets, which presents the roadway less ten meters wide, are continuously bordered in both sides by buildings that are between twelve and fourteen meters high on average.

Basic data on the roads, buildings and other features of Enna City were digitized on a scale of 25.000:1 with AcrGis software. Each segment of the road network was assigned a road code. The road code was the same of link code of CALINE 4.

To monitor the traffic flows people used Manual Classified Counts (MCCs) placed in eight point for a period of fifteen weekdays. People take in account two-wheeled motor vehicles, cars and taxis, buses and coaches, light and heavy vans for each direction of the twenty-seven roads. Figure 3 shows the bar chart of daily average and maximum traffic flows through the twenty-seven investigated roads.

As regard meteoclimatic data, people adopted the historical data series collected by meteo stations of "Enna Ambiente Company" from 1994 to 1996.

To determine the meteoclimatic conditions associated to traffic flow, it was utilized a portable meteoclimatic station (Testo 452) placed at $1,30 \mathrm{~m}$ up the ground. It was discovered that wind velocity was always less than $1,5 \mathrm{~m} / \mathrm{s}$.

To estimate the amount of polluting gasses produced along the twenty-seven roads, the "Computer Programme to calculate Emission from Road 


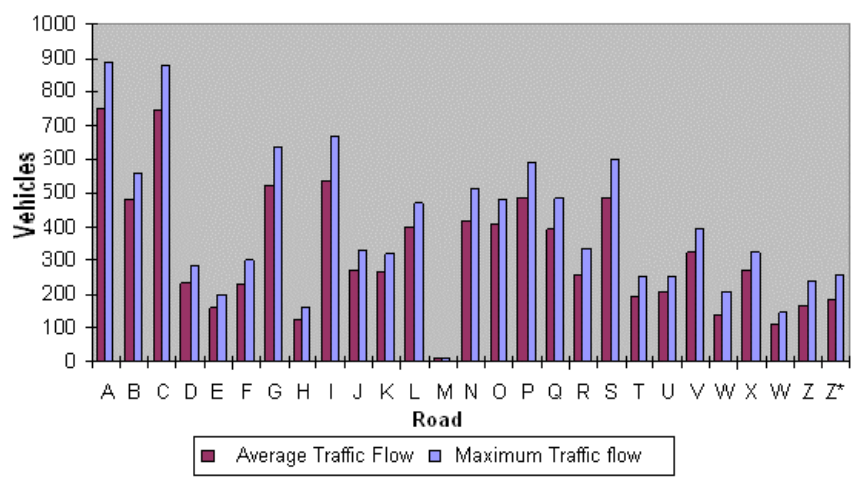

Figure 3: Daily average and maximum traffic flows.

Transport" (COPERT III) was adopted. The programme bases calculus on "emission factor approach" and values the emissions of each category of vehicles by "emission curves speed dependent". The calculus is based on the knowledge of parameters as likes as:

- Composition of circulating vehicles fleet through the investigated areas in function of both kinds of feeding (petrol, diesel oil, GPL) and regulation of reference (conventional or euro). In this case it was used data given by ACI (Automobile Club of Italy),

- The global emissions of circulating fleet.

- The cycle of drive in percentage of kind of run (urban, outside the town, motorway, etc.) the mean velocity for each cycle of drive. The velocity was determined with a campaign of measurements

- Year's run for each class of vehicle (total km/year. vehicle).

- Some other parameters as like as features of fuels, climatic conditions and so on.

COPERT III programme generates as intermediate results both the "emission factor" referred to each pollutant $(\mathrm{g} / \mathrm{km})$ for each kind of vehicle and the pollutant weigh (tons) that each kind of vehicle gives out during investigated year. In our case it was necessary to calculate "emission factor" in "main weighted mode" to take in account of real contribution that each category of vehicles gives for each polluting substance of the investigated area.

\section{Experimental measurements and equipments}

People carried out a measurement campaign of pollutant concentrations to be able to compare data forecasted by CALINE 4 quality model and those coming from measurements. Measures have been done by means of portable analyzers at the same time of the measures of traffic flows.

GRIMM MODEL 107 was utilized to measure the fractions of PM10, PM2,5 and PM 1,0 in the air while Multi Rae Plus PGM 50 was utilized to measure concentrations of various gasses $\left(\mathrm{CO}, \mathrm{CO}_{2}\right)$. 


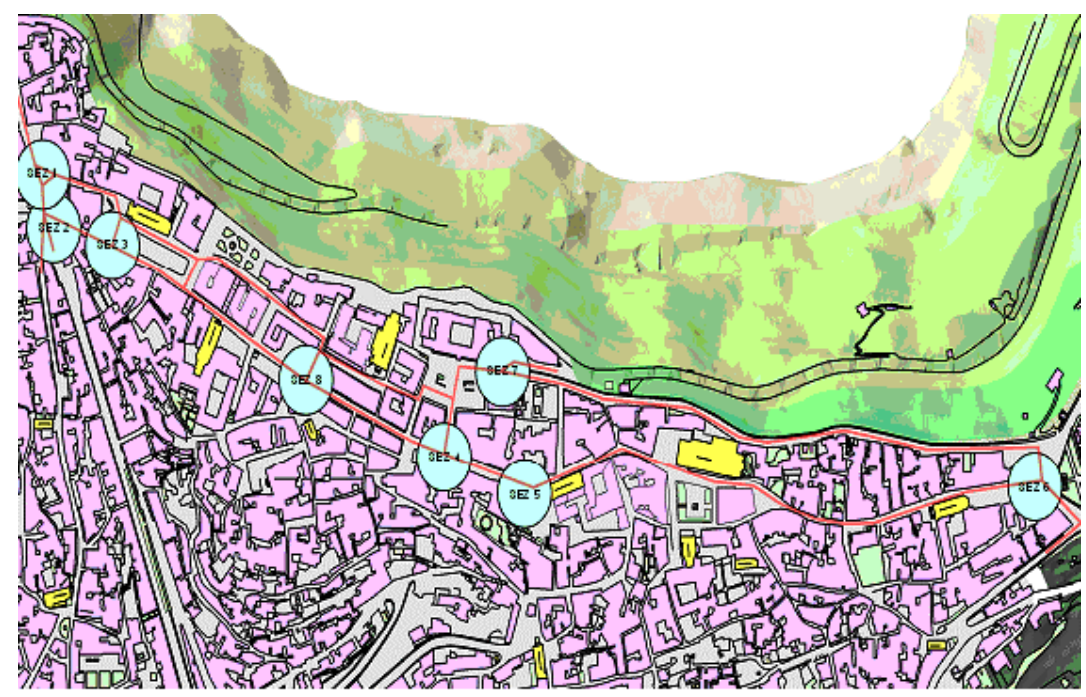

Point of measurement

Figure 4: $\quad$ Points of measurement.

Table 1: $\quad$ Exemplum of tabular datasheet.

\begin{tabular}{|c|c|c|c|c|c|}
\hline Point & Hour & $\mathrm{CO}$ & PM 10 & PM 2.5 & PM 1.0 \\
\hline \multirow{16}{*}{1} & 8.57 & \multirow{15}{*}{ AVERAGE } & 75.80 & 12.20 & 9.40 \\
\hline & 8.58 & & 55.50 & 12.00 & 8.80 \\
\hline & 8.59 & & 91.50 & 17.30 & 12.20 \\
\hline & 9.00 & & 57.10 & 18.80 & 16.20 \\
\hline & 9.01 & & 25.70 & 9.00 & 7.00 \\
\hline & 9.02 & & 42.40 & 9.30 & 6.80 \\
\hline & 9.03 & & 54.70 & 13.30 & 8.90 \\
\hline & 9.04 & & 46.90 & 13.20 & 8.30 \\
\hline & 9.05 & & 65.90 & 9.70 & 6.60 \\
\hline & 9.06 & & 30.50 & 7.40 & 5.30 \\
\hline & 9.07 & & 47.50 & 8.30 & 6 \\
\hline & 9.08 & & 39.10 & 9.40 & 6.50 \\
\hline & 9.09 & & 28.20 & 8.50 & 5.90 \\
\hline & 9.10 & & 39.60 & 7.60 & 5.50 \\
\hline & 9.11 & & 37.20 & 8.70 & 5.80 \\
\hline & 15 MIN & 19 & 49.2 & 11.0 & 7.9 \\
\hline
\end{tabular}

Figure 4 shows the map of the position of each point of measurement in the investigated area.

Both measurements of polluting gases and meteoclimatic conditions have been carried out as follows:

- Four days of measurements for each station: three in working days and one in holiday period

- Four interval of time (Observation Time) during each day of measurements, that is: $06-10 \mathrm{~h} ; 12-15 \mathrm{~h} ; 18-21 \mathrm{~h} ; 18-22 \mathrm{~h} ; 22-06 \mathrm{~h}$. 
- $\quad$ Fifteen minutes of measurements for each Observation Time

Results coming from measurements have been collected in tabular data.

Table n. 1 shows an exemplum of tabular datasheet.

\section{Dispersion model}

The modellation of investigated areas has been done by CALINE 4 Caltrans implemented by authors.

CALINE-4 is a fourth generation line source air quality model developed by the California Department of Transportation that predicts $\mathrm{CO}$ and $\mathrm{PM}_{10}$ impacts near roadways. Its main objective is to assist planners to protect public health from adverse effects of excessive $\mathrm{CO}$ and $\mathrm{PM}_{10}$ exposure. The model is based on the Gaussian diffusion equation and employs a mixing zone concept to characterize pollutant dispersion over roadways. For given source strength, meteorology, site geometry and site features the model can reliably to predict (1hour and 8-hours) pollutant concentrations for receptors located within 150 meters of the roadway.

People defined the area of study by specific calculus grid as shown in Figure 4 and in Table 2. The origin of the grid was referred to Gauss - Boaga Coordinates (2456472.819-4158201.432)

The roads network was subdivided into 60 stretches. Each of previous related sixty stretches was considered as one linear source of emission being each of them homogeneous as regard:

- Geometrical features: typology, width of carriage way and altitude with reference to local ground.

- Traffic features: yearly amount of running motor vehicles and their typology.

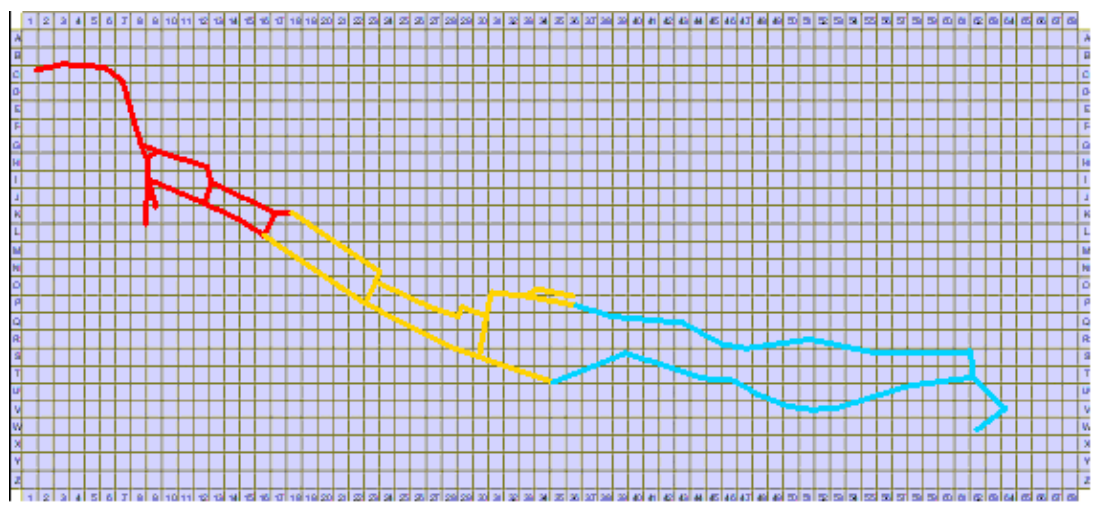

Figure 5: Calculus grid.

With reference to definition of angles of wind, people chose azimuthal ones regarding the North direction. The ruggedness of ground surfaces around the road route has been considered unvarying in all area crossed by single stretch. 
The meteorologic variables of atmospheric stability (wind velocity and direction) have been considered unvarying too for each stretch.

Table 2: $\quad$ Calculus grid.

\begin{tabular}{|l|l|}
\hline \multicolumn{2}{|c|}{ GRID } \\
\hline Origin: $x$-axis; $y$-axis & $2456472.819 \mathrm{~m} ; 4158201.432 \mathrm{~m}$ \\
\hline N point $x$-axis; $y$-axis & $84 ; 26$ \\
\hline Cell Dimension Dx Dy & $20 \mathrm{~m} ; 20 \mathrm{~m}$ \\
\hline Mean Altitude & $290 \mathrm{~m}$ \\
\hline
\end{tabular}

As regard meteoclimatic data, it was adopted one set of data linked to all "stability class" adopting wind velocity always less than $1,5 \mathrm{~m} / \mathrm{s}$ as discovered through the campaigns of measurements for investigated area. As regard wind direction, measurements in situ show a predominant wind direction orthogonal to the streets.

Table 3: Exemplum of tabular datasheet used to compare measured and forecasted $\mathrm{CO}$ concentration values.

\begin{tabular}{|c|c|c|c|c|c|c|}
\hline $\begin{array}{c}\text { Pollutant } \\
\text { CO }\end{array}$ & \multicolumn{2}{|c|}{ Measured } & \multicolumn{2}{|c|}{ Forecasted (CALINE 4) } & \multicolumn{2}{c|}{ ERROR } \\
\hline $\begin{array}{c}\text { N. } \\
\text { RECEPTOR }\end{array}$ & Start Hour & $\begin{array}{c}\text { Average Value. } \\
\text { PPM }\end{array}$ & Hour Range & $\begin{array}{c}\text { CO } \\
\text { PPM }\end{array}$ & $\begin{array}{c}\text { ASS } \\
\text { PPM }\end{array}$ \\
\hline $2 \mathrm{~B}-1$ & 08.57 & 1.9 & $09-10$ & 1.8 & 5.26 & 0.1 \\
\hline \multirow{2}{*}{$6 \mathrm{C}-2$} & 09.20 & 1.7 & $09-10$ & 1.9 & 11.76 & 0.2 \\
\cline { 2 - 7 } & 18.19 & 4.9 & $18-19$ & 4.5 & 8.16 & 0.4 \\
\hline $7 \mathrm{E}-1$ & 19.27 & 4.9 & $19-20$ & 4.7 & 4.1 & 0.2 \\
\hline \multirow{2}{*}{$8 \mathrm{G}-1$} & 09.36 & 2 & $09-10$ & 2.5 & 25 & 0.5 \\
\cline { 2 - 8 } & 18.39 & 3.5 & $18-19$ & 4.7 & 34.2 & 1.2 \\
\hline $8 \mathrm{I}-1$ & 09.54 & 1.8 & $09-10$ & 1.8 & 0 & 0 \\
\hline 9I-3 & 10.20 & 1.6 & $10-11$ & 1.7 & 6.2 & 0.1 \\
\hline 10H-1 & 17.57 & 2.2 & $18-19$ & 3.7 & 68.7 & 1.5 \\
\hline \multirow{2}{*}{$11 \mathrm{~J}-1$} & 10.36 & 1.9 & $09-10$ & 1.8 & 5.26 & 0.1 \\
\cline { 2 - 8 } & 19.09 & 2.3 & $18-19$ & 4.4 & 42.0 & 2.1 \\
\hline $12 \mathrm{I}-1$ & 09.22 & 1.4 & $09-10$ & 2.0 & 42.8 & 0.6 \\
\hline $14 \mathrm{~K}-3$ & 10.53 & 1.8 & $10-11$ & 1.9 & 5.5 & 0.1 \\
\hline $17 \mathrm{~L}-1$ & 08.09 & 3.4 & $08-09$ & 2.1 & 38.2 & 1.3 \\
\hline
\end{tabular}

The validation of model has been done through comparison between data coming from campaigns of measurements, as previously related, and the ones by application of CALINE 4 model: both data related to the same time of observation. 
Table 2 shows an exemplum of tabular datasheet used to compare measured and forecasted values.

The tabular datasheet, also, allows to determine the range of diverging, that is the divergence of the values, between the two series of data (measured and forecasted) so to discover if such a difference can cause the overcoming of limits of concentrations fixed by rules in each single receptor.

\section{Results of simulations}

Subsequently, a geostatistical interpolation technique, known as universal kriging, was employed to map the concentration of pollutants (Carbon Monoxide, Nitrogen Dioxide, and Particular Matter) over the whole area of study. The general concept is that the prediction of the value $\hat{C}(s)$ of pollutant concentration at any location s (spatial coordinates) is obtained as a weighted average of neighboured data:

$$
\hat{C}(s)=\sum_{i=1}^{n} w_{i}(s) C\left(s_{i}\right)
$$

The ultimate goal is to estimate the optimal values of the weights $\mathrm{w}_{\mathrm{i}}(\mathrm{s})$, $\mathrm{i}=1 \ldots \mathrm{n}$. This is accomplished by selecting the weights so that the expected mean square error becomes as small as possible.

So the estimation of the $\mathrm{CO}$, and $\mathrm{PM}_{10}$ concentration, using universal kriging, has required the calibration of a variogram model. Figure 5 shows the empirical variogram of $\mathrm{PM}_{10}$ daily concentration, figure 6 shows the comparison of measured and predicted daily value of $\mathrm{PM}_{10}$ while figure 7 shows the standardized error. Figure 8 displays $\mathrm{PM}_{10}$ concentration map using Kriging geostatistical interpolation. Four main hot spot area of maximum concentration can be identified in the $\mathrm{PM}_{10}$ pollution map. Table 3 summarize the prediction errors of the universal kriging estimates for $\mathrm{PM}_{10}$ concentration

Table 4: $\quad$ Prediction errors of universal kriging for $\mathrm{PM}_{10}$ concentration.

\begin{tabular}{|l|c|}
\hline \multicolumn{1}{|c|}{ Prediction Error } & Value \\
\hline Mean & -0.002684 \\
\hline Root Mean Square & 4.625 \\
\hline Average standard Error & 4.11 \\
\hline Mean standardized & -0.003464 \\
\hline Root Mean Square Standardized & 1.127 \\
\hline
\end{tabular}

The value of mean error $(-0.002684)$ being close to zero, indicates that the predicted values are unbiased. Similar information is provided by the mean standardized prediction error (-0.003464). Also, the average standard error $(4,11)$ is lower than the root-mean square of predicted errors (4.625). This shows that our model slightly under-estimates the variability of $\mathrm{PM}_{10}$ concentration. The root-mean square prediction error is a measure of the error that occurs when predicting data from point observations and provides the means for deriving 
confidence intervals for the predictions. Finally the root mean square standardized (1.127) is very close to 1 , and thus corresponds to a very good fit between the point estimates of CALINE 4 and the geostatistical model using universal kriging.

Table 4 summarize the prediction errors of the universal kriging estimates for $\mathrm{CO}$ concentration

Table 5: $\quad$ Prediction errors of universal kriging for $\mathrm{PM}_{10}$ concentration.

\begin{tabular}{|l|c|}
\hline \multicolumn{1}{|c|}{ Prediction Error } & Value \\
\hline Mean & 0.0000568 \\
\hline Root Mean Square & 0.05256 \\
\hline Average standard Error & 0.05475 \\
\hline Mean standardized & 0.0004092 \\
\hline Root Mean Square Standardized & 0.9666 \\
\hline
\end{tabular}

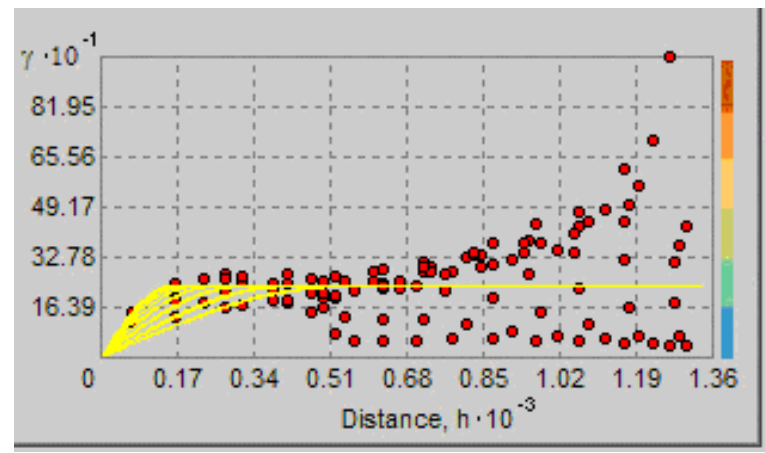

Figure 6: Variogram of $\mathrm{PM}_{10}$ daily concentration with average traffic flow.

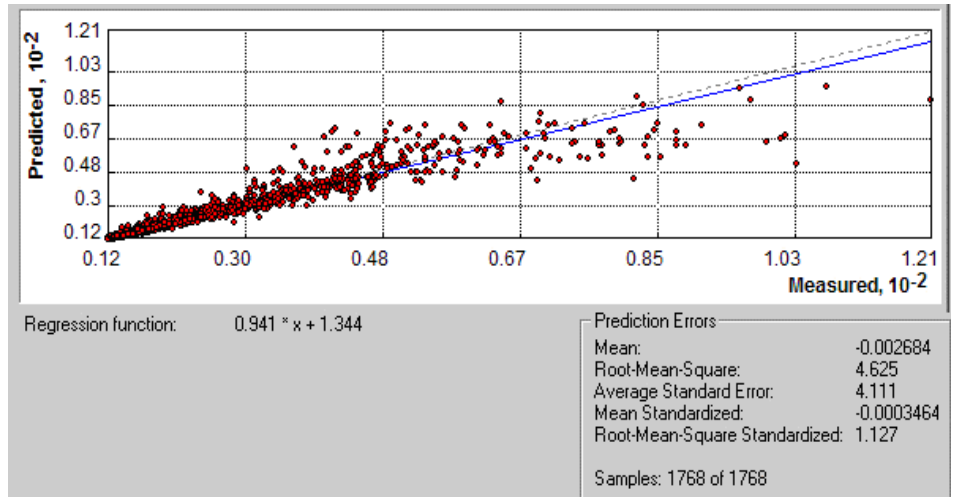

Figure 7: Comparison of measured and predicted daily value of $\mathrm{PM}_{10}$ with average traffic flow. 
Like so $\mathrm{PM}_{10}$ concentration, the value of mean error (0.0000568) and the mean standardized prediction error (0.000409) are very close to zero. On the other way, the average standard error (0.05475) is greater than the root-mean square of predicted errors (0.05256). This shows that our model over-estimates the variability of $\mathrm{CO}$ concentration. Finally, the root mean square standardized (0.966) is very close to 1 , and thus corresponds to a very good fit between the point estimates of CALINE 4 and the geostatistical model using universal kriging.

Figure 9 displays $\mathrm{CO}$ concentration map using Kriging geostatistical interpolation.

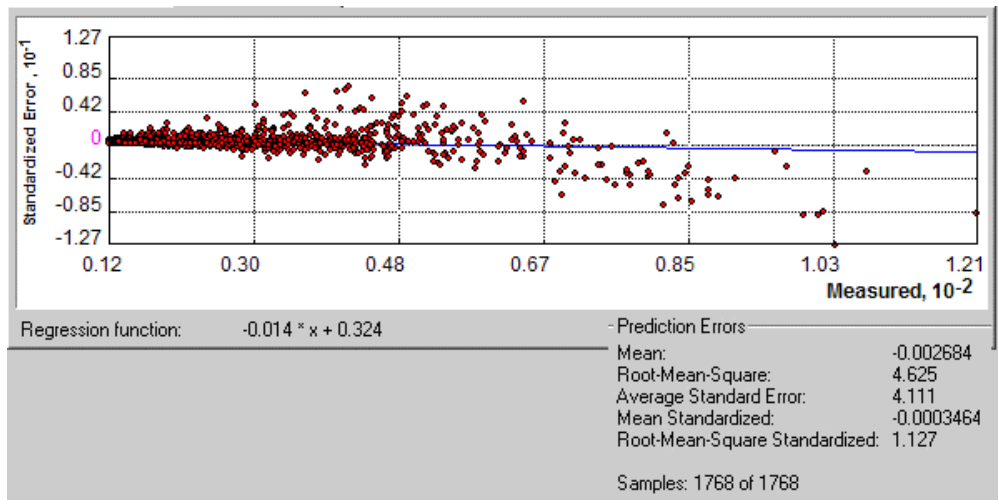

Figure 8: The standardized error of the interpolated map of $\mathrm{PM}_{10}$ concentration.

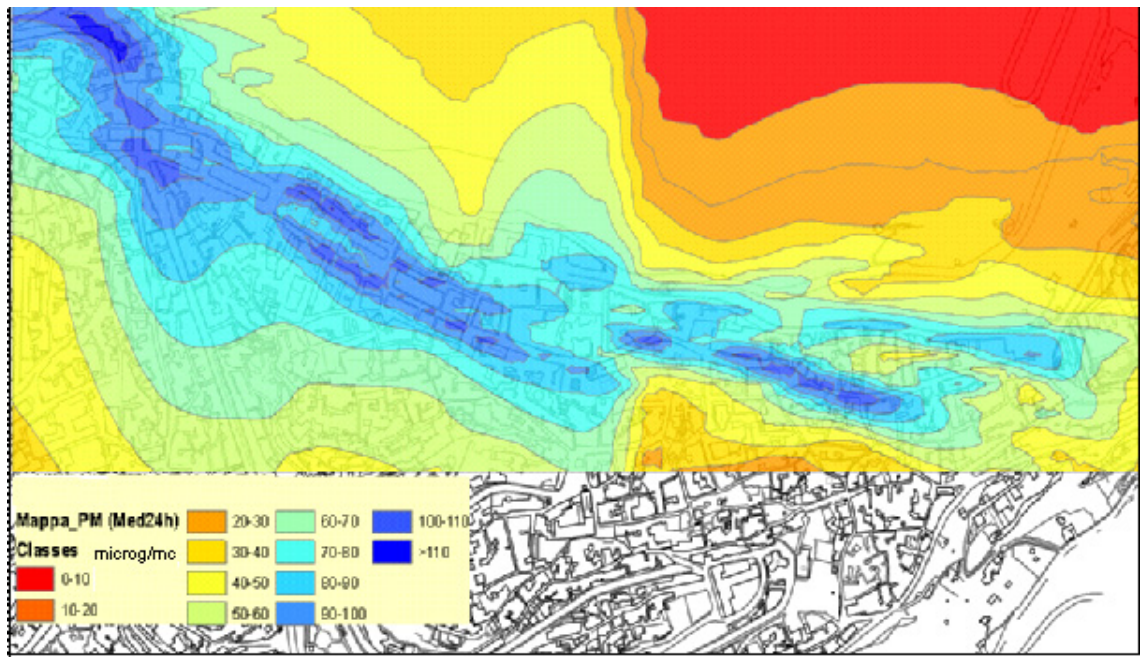

Figure 9: $\quad$ Map of $\mathrm{PM}_{10}$ daily concentration. 


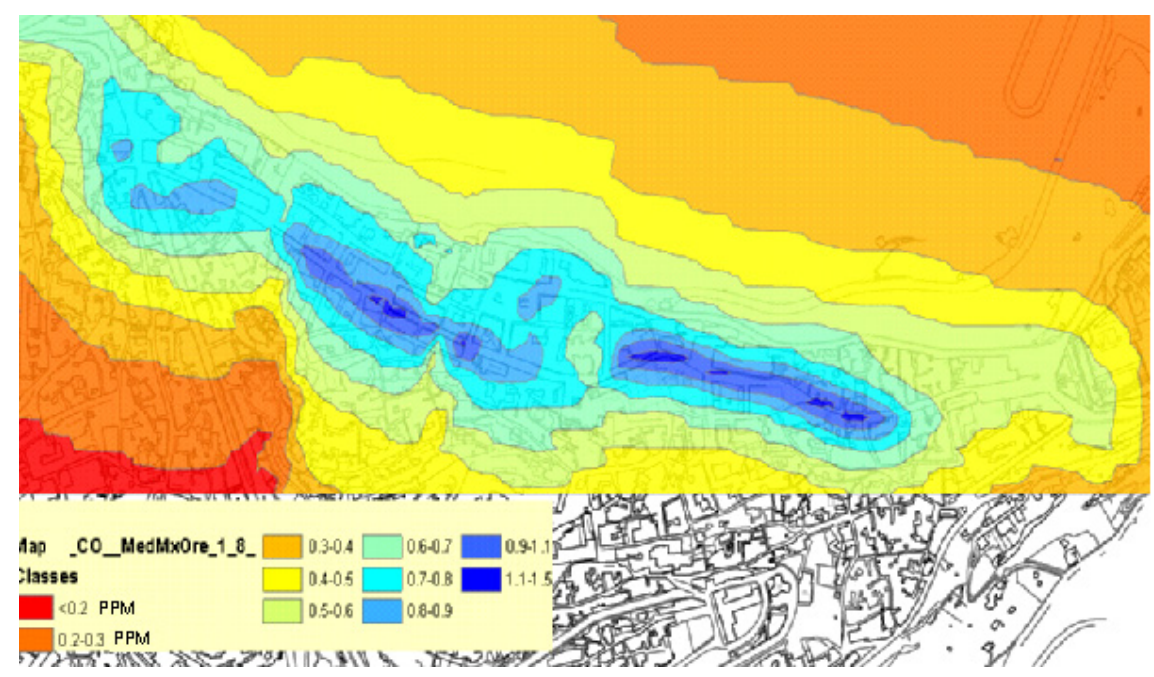

Figure 10: Map of CO concentration (8h).

\section{Conclusions}

This paper has described a methodology that provides to estimate vehicular air pollution and mapping using the CALINE 4 dispersion model and spatial data analysis. Forecasted traffic volumes and emission factors are used as input to CALINE 4, which estimates $\mathrm{CO}$ and $\mathrm{PM}_{10}$ concentrations at predefined point locations. Afterwards, universal kriging implemented by AcrGis is used to estimate and map the concentration of the pollutants over the study area. The results of this research show that the visualization and analytical features of GIS provide more information and convenience to users. It also makes the model more efficient and flexible.

The results presented in this paper are preliminary outcomes of ongoing research. The model will be further developed, e.g. expanding its submodels to include things such as transportation models and risk assessment models, with the eventual goal being to develop an Urban Air Quality Decision Support System.

\section{References}

[1] USEPA (1998). A GIS based modal model of automobile exhaust emissions. USEPA Report No. EPA-600/-98 -097, Research Triangle Park, NC (USA).

[2] European Environment Agency, "COPERTIII - Methodology and emission factors" Anno 2000

[3] European Environment Agency, “COPERTIII-User's manual” Anno 2000

[4] California Department Of Transportation, " CALINE4 - A dispersion Model for Predicting Air Pollution Concentrations Near Roadways" 1984 
[5] California Department Of Transportation, “ User's guide for CL4: a user friendly interface for the CALINE4 model for transportation project impact assessment" giugno 1998

[6] Autoritratto ACI - Provincia Enna, 2002

[7] Agenzia Nazionale per la Prevenzione e l'Ambiente, "Le emissioni in atmosfera da trasporto stradale”, Serie Stato dell'ambiente, n.12, 2000

[8] ENEA, ERG-SIRE DBT, Dati Temperatura Enna 2000

[9] ENNA AMBIENTE, Monitoraggi Ambientali Periodo 1994-96

[10] Johnston, Ver Hoef, "Using ArcGis Geostatistical Analyst”, GIS by ESRI 